\title{
Vesicoureteric reflux: screening of first degree relatives
}

\author{
V K AGGARWAL AND K VERRIER JONES \\ Department of Child Health, Royal Infirmary, Cardiff
}

SUMMARY Thirty three healthy infants and children with a family history of reflux nephropathy or vesicoureteric reflux in first degree relatives were screened for upper urinary tract abnormalities (renal scarring or pelvicaliceal dilatation) using ultrasound scanning or intravenous urography, or both. In addition, micturating cystourethrography was carried out in all infants and children under 2 years old $(n=20)$ and in children over 2 years old in whom abnormalities of the upper renal tract (renal scarring) had been found $(n=3)$. Upper renal tract abnormalities were found in four of the total of 33 children $(12 \%)$ and vesicoureteric reflux in 12 of the 23 who underwent micturating cystourethrography $(52 \%)$. Screening of infants and children was acceptable to parents. This approach has enabled the diagnosis of vesicoureteric reflux to be made in an appreciable number of children before the development of urinary tract infections and reflux nephropathy. Prospective follow up of this group will provide more information about the natural history of sterile vesicoureteric reflux.

The association of vesicoureteric reflux, urinary tract infection, and reflux nephropathy is well established. ${ }^{1}$ Reflux nephropathy is thought to account for at least $10 \%$ of cases of end stage renal disease. $^{2}$ This may be an underestimate, as reflux nephropathy is commonly underdiagnosed. The incidence of hypertension in children with reflux nephropathy is between $5 \%$ and $30 \% .{ }^{34}$ In infants with vesicoureteric reflux renal damage commonly follows urinary tract infection. When vesicoureteric reflux is diagnosed in an infant after the first urinary tract infection scarring in susceptible areas of the kidney may already be developing so that attempts to prevent renal damage by giving prophylactic antibiotics or by reimplanting the ureters are made after the initial damage has occurred. Late presentation of patients with end stage renal disease as a result of reflux nephropathy is common, and some have little or no history of preceding urinary tract infection. ${ }^{5}$ In these children, the urinary tract infection may have been present but undiagnosed or, alternatively, damage may have been caused by sterile vesicoureteric reflux. ${ }^{6}$ As vesicoureteric reflux is normally detected after the presenting infection there has been little opportunity to observe the natural history of sterile vesicoureteric reflux in children.

There have been a number of reports indicating the familial nature of vesicoureteric reflux. ${ }^{7}$ Investigation of the HLA system has shown that haplo-? types A2-B8 and A9-B12 occur more commonly in children with reflux nephropathy. ${ }^{89}$ Because of the evidence in favour of a familial tendency for vesicoureteric reflux and reflux nephropathy, it is appropriate to give genetic counselling to affected families so that they are aware of potential problems such as the risk of urinary tract infection, vesicoureteric reflux, and reflux nephropathy, as well as the complications of reflux nephropathy. Nevertheless screening for vesicoureteric reflux is not recommended routinely.

Smellie et al reported that long term prophylaxis in children with symptomatic urinary tract infections prevented reinfection and aided renal growth. ${ }^{10}$ Children with vesicoureteric reflux during infancy and early childhood are more prone to develop reflux nephropathy following urinary tract infections and hence long term prophylaxis is indicated in the most vulnerable group of children - those under 2 years of age. This report describes our clinical experience in counselling families with reflux nephropathy or vesicoureteric reflux.

\section{Patients and methods}

Twenty seven families in which one member had 
vesicoureteric reflux, or reflux nephropathy, or both, were counselled about the familial risk of vesicoureteric reflux and the subsequent risk of reflux nephropathy, as well as the risk and symptoms of urinary tract infection, particularly in infancy. Two groups of children were studied. Group A comprised 17 children born to 15 affected mothers, 14 of whom had been identified in childhood during a programme of screening for bacteriuria. ${ }^{11}$ The remaining mother had had a urinary tract infection in childhood and had subsequently presented with hypertension in pregnancy caused by reflux nephropathy. Group B comprised 16 siblings of 11 children who presented with clinically apparent urinary tract infection.

Ultrasound examination of the kidneys and bladder was undertaken in every case to assess renal size, the presence of pelvicaliceal dilatation and

Table 1 Infants and children of parents (index cases) with reflux nephropathy or vesicoureteric reflux

\begin{tabular}{|c|c|c|c|c|c|}
\hline $\begin{array}{l}\text { Diagnosis of } \\
\text { index case }\end{array}$ & $\begin{array}{l}\text { Case } \\
\text { No }\end{array}$ & Age & Sex & $\begin{array}{l}\text { Findings on } \\
\text { intravenous urography } \\
\text { or ultrasound } \\
\text { scanning }\end{array}$ & $\begin{array}{l}\text { Findings on micturating } \\
\text { cystourethrography }\end{array}$ \\
\hline Reflux nephropathy & 1 & 3 Weeks & Male & Normal & Normal \\
\hline Vesicoureteric reflux & 2 & 1 Month & Female & Normal & Refused \\
\hline Reflux nephropathy & 3 & 6 Weeks & Female & Normal & Bilateral vesicoureteric reflux grade II \\
\hline Reflux nephropathy & 4 & 2 Months & Female & Dilated calyces & Normal \\
\hline Reflux nephropathy & 5 & 2 Months & Female & Normal & Normal \\
\hline Reflux nephropathy & 6 & 2 Months & Female & Normal & Normal \\
\hline Reflux nephropathy & 7 & 3 Months & Female & Normal & Normal \\
\hline Reflux nephropathy & 8 & 3 Months & Male & Normal & Refused \\
\hline Reflux nephropathy & 9 & 4 Months & Male & Normal & Normal \\
\hline Reflux nephropathy & 10 & 6 Months & Female & Normal & Bilateral vesicoureteric reflux grade II \\
\hline Reflux nephropathy & 11 & 7 Months & Female & Normal & Bilateral vesicoureteric reflux grade II \\
\hline Reflux nephropathy & 12 & 10 Months & Male & Normal & Bilateral vesicoureteric reflux grade I \\
\hline Reflux nephropathy & 14 & 16 Months & Male & Normal & Bilateral vesicoureteric reflux grade I \\
\hline Reflux nephropathy & 15 & 3 Years & Female & Normal & Not done \\
\hline Reflux nephropathy & 16 & 4 Years & Male & Normal & Not done \\
\hline Reflux nephropathy & 17 & 4 Years & Male & Normal & Not done \\
\hline
\end{tabular}

Table 2 Siblings of children (index cases) with reflux nephropathy or vesicoureteric reflux

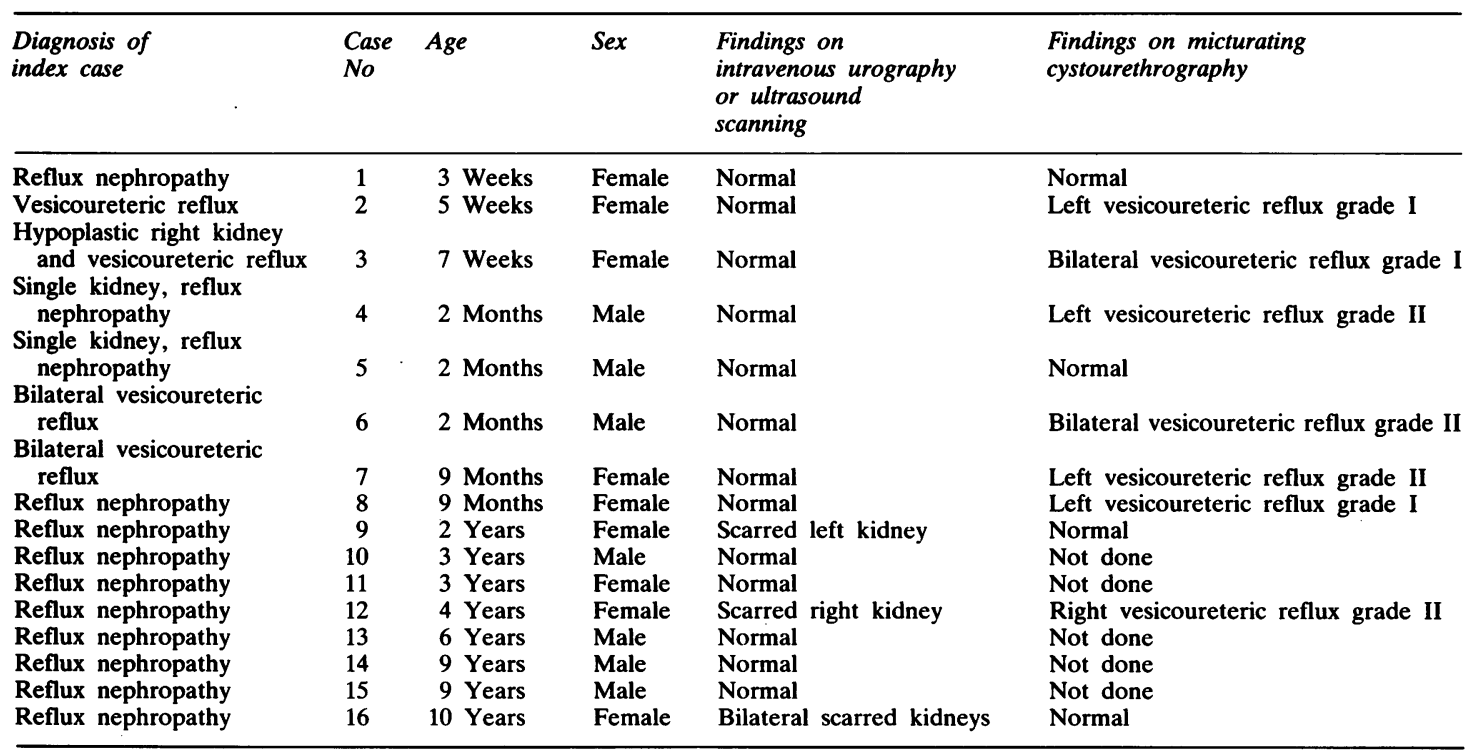


gross renal scarring. Four children also underwent intravenous urography before 1984 when experience in ultrasound examination was limited. Infants and children under 2 years of age were advised to undergo micturating cystourethrography, which was also recommended in older children if upper tract abnormality such as pelvicaliceal dilatation or renal scarring had been detected on intravenous urography or ultrasound examination. The grading of vesicoureteric reflux was classified according to the recommendations of the Medical Research Council Bacteriuria Committee. ${ }^{12}$ To reduce the risk of urinary tract infection trimethoprim $2 \mathrm{mg} / \mathrm{kg}$ was given in three doses at 12 hour intervals, one dose before and two after catheterisation, to all children undergoing micturating cystourethrography. Children under the age of 2 years in whom vesicoureteric reflux was detected were advised to take low dose prophylaxis with trimethoprim, 1 to $2 \mathrm{mg} / \mathrm{kg}$ /day until the age of 2 years. These cases are reviewed individually after the age of 2 years and a decision then made about stopping or continuing the prophylaxis, depending on whether breakthrough infections occurred during the period of follow up.

\section{Results}

In Group $A$ the acceptability of micturating cystourethrography was $86 \%$, whereas in group B it was $100 \%$. Four of the total of 33 children $(12 \%)$ had an abnormality of the upper renal tract (one child had a dilated caliceal system and three had scarring of kidneys). Twelve out of the 23 children who underwent micturating cystourethrography $(52 \%)$ had vesicoureteric reflux. Ten of these children were under 1 year of age. The reflux was grade I in five cases and grade II in seven cases. Fifteen of 33 children $(45 \%)$ showed some abnormality of the renal tract on ultrasound examination or micturating cystourethrography, or both (tables 1 and 2). All six abnormalities found in group A and six of the nine in group $B$ were in children under 2 years of age.

\section{Discussion}

To justify screening it is necessary to detect an early form of a condition so that serious problems can be prevented. Our knowledge of the natural history of reflux nephropathy suggests that this may be the case in this condition. Although it may be possible to prevent renal damage in healthy infants with vesicoureteric reflux by preventing urinary tract infection with long term low dose prophylaxis, this has not been proved. Despite the fact that grade I vesicoureteric reflux has a high spontaneous resolution rate and may not be well correlated with reflux nephropathy, we have recommended chemoprophylaxis as all these children were in the most vulnerable age group, that is, under 2 years of age.

Twenty four families, all of whom had previous experience of micturating cystourethrography, allowed their children to undergo this examination. The acceptability was $100 \%$ if other siblings had already had clinical problems (group B). In group $A$, in which index cases were asymptomatic women who were diagnosed in a bacteriuria survey during childhood and who had few problems except during pregnancy, the acceptability was slightly lower $(86 \%)$. The cost effectiveness of this type of programme cannot be assessed from this study as it is not possible to detect how many scars have been prevented. Because over half of those infants investigated by micturating cystourethrography had vesicoureteric reflux, however, the potential for the prevention of scarring is considerable. In addition, older children with established reflux nephropathy were also identified. In these children a diagnosis of urinary tract infection had never been previously considered. In this group it was possible to give advice about the risk of progression of scarring, hypertension, and possible complications during pregnancy.

The diagnosis of urinary tract infection in infants is not easy, as symptoms are rarely localised to the urinary tract. Unless an infant is referred to hospitaf for investigations, urine is rarely examined for a urinary tract infection within the community. During the process of counselling and screening, families are instructed to consider the possibility of urinary tract infection if their infant becomes ill, and arrangements are made through the general practitioner or by direct access to the ward to check the urine when necessary. Selective screening for vesicoureteric reflux has enabled us to identify a population who are at high risk of developing reflux nephropathy, and to follow them up prospectively. With this technique it is possible to improve the degree of health care provided for those children who are at greatest risk of developing reflux nephropathy. Long term follow up of these infants will enable more to be learnt about the natural history of sterile vesicoureteric reflux.

We thank the Laura Ashley Foundation for financial support, the department of radiology, Cardiff Royal Infirmary, for undertaking the investigations, and Miss J Cook for secretarial assistance.

\footnotetext{
References

1 Bailey RR. An overview of reflux nephropathy. In: Hodson C J Kincaid-Smith P, eds. Reflux nephropathy. New York: Masson, 1979:3-13.

2 Donckerwolcke RA, Brunner FP. Combined report on regular
} 
dialysis and transplantation of children in Europe 1981. Proceedings of the European Dialysis and Transplant Association. Volume 20. London: Pitman Medical, 1982:60-91.

${ }^{3}$ Bachman H. Hypertension: a frequent complication in children and adolescents with reflux nephropathy. Klin Padiatr 1982;194: $152-8$.

4 Bailey RR. Reflux nephropathy and hypertension. In: Hodson CJ, Kincaid-Smith P, eds. Reflux nephropathy, New York: Masson, 1979:263-7.

${ }^{5}$ Heale WF, Shannon FT, Utley WLF, Rolleston GL. Familial and hereditary reflux nephropathy. In: Hodson CJ, KincaidSmith P, eds. Reflux nephropathy. New York: Masson, 1979: 48-52.

${ }^{6}$ Ransley PG, Risdon RA, Godley ML. High pressure sterile vesicoureteric reflux and renal scarring: an experimental study in the pig and minipig. In: Hodson CJ, Hepinstall RM, Winberg J, eds. Reflux nephropathy update 1983. London: Karger, 1984:320-43.

${ }^{7}$ Bailey RR, Janus E, McLoughlin K, Lynn KL, Abbott GD. Familial and genetic data in reflux nephropathy. In: Hodson CJ, Hepinstall RM, Winberg J, eds. Reflux nephropathy update 1983. London: Karger, 1984:40-51.
${ }^{8}$ Bailey RR, Wallace M. HLA-B12 as a genetic marker for vesicoureteric reflux? Br Med J 1978;i:48-9.

${ }^{9}$ Torres VE, Moose SB, Kurtz SB, Offord KP, Kelalis PP. In search of a marker for genetic susceptibility to reflux nephropathy. Clin Nephrol 1980;14:217-20.

10 Smellie JM, Edwards D, Normand ICS, Prescod N. Effect of vesicoureteric reflux on renal growth in children with urinary tract infection. Arch Dis Child 1981;56:593-8.

11 McLachlan MSF, Meller ST, Verrier Jones ER, et al. Urinary tract in schoolgirls with covert bacteriuria. Arch Dis Child 1975;50:253-8.

12 A Report by the members of the Medical Research Council Bacteriuria Committee. Recommended terminology of urinary tract infection. Br Med J 1979;ii:717-9.

Correspondence to Dr K Verrier Jones, Department of Child Health, Royal Infirmary, Cardiff CF2 ISZ.

Accepted 29 June 1989 